\title{
A Novel Multi-Criteria Decision Making Method for Evaluating Water Reuse Applications under Uncertainty
}

\section{Le Thi Nhung and Nguyen Xuan Thao}

Faculty of Information Technology, Vietnam National University of Agriculture, Hano 131000, Vietnam

\begin{abstract}
There are currently many places in the world where water is scarce. Therefore, water reuse has been mentioned by many researchers. Evaluation of water reuse applications is the selection of the best water reuse application of the existing options; it is also one of the applications of multi-criteria decision making (MCDM). In this paper, we introduce a new dissimilarity measure of picture fuzzy sets. This new measure overcomes the restriction of other existing dissimilarity measures of picture fuzzy sets. Then, we apply it to the multi-criteria decision making. Finally, we refer to a new method for selecting the best water reuse application of the available options by using the picture fuzzy MCDM.
\end{abstract}

\section{Keywords}

Multi-criteria decision making, picture fuzzy, water reuse

\section{Introduction}

Reuse of water refers to the treatment and rehabilitation of nontraditional or deteriorated water for beneficial purposes (Miller, 2006). Water reuse is synonymous with using reclaimed water, which can provide an option to reduce water scarcity, especially under the new reality of climate change and the increase in human activities. Water reuse has become widespread all over the world to solve the depletion of water resources, leading to reduced water supplies. Evaluation of water reuse applications is a weight replacement process and the most appropriate selection of water reuse applications. From this, the assessment involves analyzing many criteria with social, technical, economic, political, environmental, and technical aspects to ensure sustainable decision making (Zarghami and Szidarovszky, 2009). The challenge with water reuse application evaluation (WRAE) is that alternatives are diverse in nature, and often have conflicting criteria. The fuzzy set theory (Zadeh, 1965) is a very effective method for solving such contradictory and uncertain problems. 
Fuzzy set theory was introduced by Zadeh in 1965. Immediately, it became a useful method to study the problems of imprecision and uncertainty. Since then, many new theories treating imprecision and uncertainty have been introduced. For instance, an intuitionistic fuzzy set was introduced in 1986 (Atanassov, 1986), which is a generalization of the notion of a fuzzy set. While fuzzy set gives the degree of membership of an element in a given set, the intuitionistic fuzzy set gives a degree of membership and a degree of non-membership. Picture fuzzy set (Cuong and Kreinovich, 2013) is an extension of the crisp set, fuzzy set, and intuitionistic set. A picture fuzzy set has three memberships: a degree of positive membership, a degree of negative membership, and a degree of neutral membership of an element in this set. This approach is widely used by researchers in both theory and application. Hoa and Thong (2017) improved fuzzy clustering algorithms using picture fuzzy sets and applications for geographic data clustering. Son (2015) and Son (2017) presented an application of picture fuzzy set in the problem of clustering. Dinh et al. (2015) introduced the picture fuzzy database and examples of using the picture fuzzy database. Dinh et al. (2017) investigated distance measures and dissimilarity measures on picture fuzzy sets and applied them in pattern recognition. But these dissimilarity measures of Dinh et al. (2017) have a restriction that is further explored in the next section.

We often use decision making methods because of the uncertainty and complexity of the nature of decision making. By the multi-criteria decision making (MCDM) methods, we can determine the best alternative from multiple alternatives for a set of criteria. In recent times, the choice of suppliers has increasingly played an important role in both academia and industry. Therefore, there are many MCDM techniques developed for the supplier selection (Bhutia and Phipon, 2012; Jadidi et al., 2010; Yildiz and Yayla, 2015). However, the above methods have limited use in set theory. Therefore, it is difficult to encounter problems of uncertain or incomplete data. There are several authors who have proposed MCDM methods using fuzzy set theory or intuitionistic fuzzy set for the supplier selection (Boran et al., 2009; Kavita et al., 2009; Yayla, 2012; Maldonado-Macías et al., 2014; Pérez et al., 2015; Omorogbe, 2016; Solanki et al., 2016; Zeng and Xiao, 2016).

With the considered criteria for water reuse applications (Pan et al., 2018), there are usually three levels. For example, the public acceptability attribute has three levels: agreement, disagreement, and neutrality; here we consider the level of agreement as the degree of positive membership, level disagreement as the degree of negative membership, and level neutrality as the degree of neutral membership of the criteria of public acceptability in each alternative. Therefore, we use the multi-criteria decision making method based on picture fuzzy set to select the best alternative in evaluating water reuse applications.

In this paper, we propose a new dissimilarity measure of picture fuzzy sets. This measure overcomes the restriction of the four dissimilarity measures of picture fuzzy sets introduced by Dinh et al. (2017). We then propose a MCDM based on the new dissimilarity measure and apply it for evaluating the water reuse applications under uncertainty.

The rest of the paper is organized as follows: In the next section, we recall the concept of picture fuzzy set and several operators of two picture fuzzy sets. We then propose a new MCDM method using the dissimilarity measure of picture fuzzy sets. Finally, we apply the proposed method for evaluating water reuse applications.

\section{Preliminaries}

\section{Picture fuzzy sets}

Definition 1 (Cuong and Kreinovich, 2013). Let $U$ be a universal set. A picture fuzzy set (PFS) $A$ on the $U$ is $A=$ $\left\{\left(u, \mu_{A}(u), \eta_{A}(u), \gamma_{A}(u)\right) \mid u \in U\right\}$ where $\mu_{A}(u)$ is called the "degree of positive membership of $u$ in $A$ ", $\eta A x(\in 0,1)$ is called the "degree of neutral membership of $u$ in $A$ ", and $\gamma_{A}(u) \gamma \operatorname{Ax}(\in 0,1)$ is called the "degree of negative membership of $u$ in $A$ " where $\mu_{A}(u), \eta_{A}(u)$, and $\mu \mathrm{A}, \gamma \mathrm{A} \gamma_{A}(u) \in$ $[0,1] \quad \eta$ Asatisfy the following condition: 
$0 \leq \mu_{A}(u)+\eta_{A}(u)+\gamma_{A}(u) \leq 1, \forall u \in U$.

The family of all picture fuzzy sets in $U$ is denoted by $\operatorname{PFS}(U)$.

For convenience in this paper, we call $P$ is a picture fuzzy number where $P=(a, b, c)$ in which $a, b, c \geq 0$ and $a+b+c \leq 1$.

Definition 2 (Cuong and Kreinovich, 2013). The picture fuzzy set $B=$ $\left\{\left(u, \mu_{B}(u), \eta_{B}(u), \gamma_{B}(u)\right) \mid u \in U\right\} \quad$ is called the subset of the picture fuzzy set $A=$ $\left\{\left(u, \mu_{A}(u), \eta_{A}(u), \gamma_{A}(u)\right) \mid u \in U\right\}$ iff $\mu_{B}(u) \leq \mu_{A}(u), \eta_{B}(u) \leq \eta_{A}(u)$ and $\gamma_{B}(u) \geq \gamma_{A}(u)$ for all $u \in U$.

Definition 3 (Cuong and Kreinovich, 2013). The complement of picture fuzzy set $A=$ $\left\{\left(u, \mu_{A}(u), \eta_{A}(u), \gamma_{A}(u)\right) \mid u \in U\right\}$ is

$A^{C}=\left\{\left(u, \gamma_{A}(u), \eta_{A}(u), \mu_{A}(u)\right) \mid u \in U\right\}$.

Definition 4 (Cuong and Kreinovich, 2013). Let $A, B$ be two picture fuzzy sets on $U$. Then

$A \cup B=\left\{\left(u, \max \left\{\mu_{A}(u), \mu_{B}(u)\right\}, \min \left\{\eta_{A}(u), \eta_{B}(u)\right\}, \min \left\{\gamma_{A}(u), \gamma_{B}(u)\right\}\right) \mid u \in U\right\}$ and

$A \cap B=\left\{\left(u, \min \left\{\mu_{A}(u), \eta_{B}(u)\right\}, \min \left\{\eta_{A}(u), \eta_{B}(u)\right\}, \max \left\{\gamma_{A}(u), \gamma_{B}(u)\right\}\right) \mid u \in U\right\}$.

\section{New dissimilarity measure of picture fuzzy sets}

Firstly, we recall the concept of dissimilarity measure for picture fuzzy sets:

Definition 5 (Dinh et al., 2017). A function DIS: $P F S(U) \times P F S(U) \rightarrow[0,1]$ is a dissimilarity measure between PFS-sets if it satisfies the following properties:

PF-Diss 1: $D I S(A, B)=\operatorname{DIS}(B, A)$;

PF-Diss 2: $D I S(A, A)=0$;

PF-Diss 3: If $A \subset B \subset C$ then $D I S(A, C) \geq \max \{\operatorname{DIS}(A, B), D I S(B, C)\}$.

Now, we propose the new dissimilarity measure for picture fuzzy sets:

Definition 6: Let $U=\left\{u_{1}, u_{2}, \ldots, u_{N}\right\}$ be the universe set. Let $w_{i}$ be the weight of element $u_{i}$ of $U$ in which $0 \leq w_{i} \leq 1$ and $\sum_{i=1}^{N} w_{i}=1$. Given two picture fuzzy sets $A=$ $\left\{\left(u_{i}, \mu_{A}\left(u_{i}\right), \eta_{A}\left(u_{i}\right), \gamma_{A}\left(u_{i}\right)\right) \mid u_{i} \in U\right\}$ and $B=\left\{\left(u_{i}, \mu_{B}\left(u_{i}\right), \eta_{B}\left(u_{i}\right), \gamma_{B}\left(u_{i}\right)\right) \mid u_{i} \in U\right\}$, we denote

$D I S_{E}(A, B)=\sum_{i=1}^{N} w_{i} D I S_{E}^{i}(A, B)$

where

$D I S_{E}^{i}(A, B)=\frac{1-e^{-\left|\mu_{A}\left(u_{i}\right)-\mu_{B}\left(u_{i}\right)\right|}+\left|\eta_{A}\left(u_{i}\right)-\eta_{B}\left(u_{i}\right)\right|+\left|\gamma_{A}\left(u_{i}\right)-\gamma_{B}\left(u_{i}\right)\right|}{3}(i=1,2, \ldots, N)$.

Theorem 1: The formula $D I S_{E}(A, B)$ determined in Eq.(1) is a dissimilarity measure of two picture fuzzy sets $A$ and $B$.

\section{Proof.}

We have $0 \leq \mu_{A}\left(u_{i}\right), \mu_{B}\left(u_{i}\right), \eta_{A}\left(u_{i}\right), \eta_{B}\left(u_{i}\right), \gamma_{A}\left(u_{i}\right), \gamma_{B}\left(u_{i}\right) \leq 1$ for all $i=1,2, \ldots, N$. Hence, $0 \leq$ $D I S_{E}^{i}(A, B) \leq 1$ for all $i=1,2, \ldots, N$. This implies that $0 \leq D I S_{E}(A, B) \leq 1$.

It is easily verified that:

+ PF-Diss 1: $D I S(A, B)=D I S(B, A)$;

+ PF-Diss 2: $D I S(A, A)=0$;

+ With PF-Diss 3, if $A \subset B \subset C$ we have

$\left\{\begin{array}{l}\mu_{A}\left(u_{i}\right) \leq \mu_{B}\left(u_{i}\right) \leq \mu_{C}\left(u_{i}\right) \\ \eta_{A}\left(u_{i}\right) \leq \eta_{B}\left(u_{i}\right) \leq \eta_{C}\left(u_{i}\right) \\ \gamma_{A}\left(u_{i}\right) \geq \gamma_{B}\left(u_{i}\right) \geq \gamma_{C}\left(u_{i}\right)\end{array}\right.$

for all $u_{i} \in U$.

So that, we have 
$\max \left\{\left|\mu_{B}\left(u_{i}\right)-\mu_{A}\left(u_{i}\right)\right|,\left|\mu_{C}\left(u_{i}\right)-\mu_{B}\left(u_{i}\right)\right|\right\} \leq\left|\mu_{A}\left(u_{i}\right)-\mu_{C}\left(u_{i}\right)\right|$, $\max \left\{\left|\eta_{B}\left(u_{i}\right)-\eta_{A}\left(u_{i}\right)\right|,\left|\eta_{C}\left(u_{i}\right)-\eta_{B}\left(u_{i}\right)\right|\right\} \leq\left|\eta_{A}\left(u_{i}\right)-\eta_{C}\left(u_{i}\right)\right|$,

and

$\max \left\{\left|\gamma_{B}\left(u_{i}\right)-\gamma_{A}\left(u_{i}\right)\right|,\left|\gamma_{C}\left(u_{i}\right)-\gamma_{B}\left(u_{i}\right)\right|\right\} \leq\left|\gamma_{A}\left(u_{i}\right)-\gamma_{C}\left(u_{i}\right)\right|$

for all $u_{i} \in U$.

It is also implies that

$\max \left\{1-e^{-\left|\mu_{B}\left(u_{i}\right)-\mu_{A}\left(u_{i}\right)\right|}, 1-e^{-\left|\mu_{C}\left(u_{i}\right)-\mu_{B}\left(u_{i}\right)\right|}\right\} \leq 1-e^{-\left|\mu_{A}\left(u_{i}\right)-\mu_{C}\left(u_{i}\right)\right|}$, $\max \left\{\left|\eta_{B}\left(u_{i}\right)-\eta_{A}\left(u_{i}\right)\right|,\left|\eta_{C}\left(u_{i}\right)-\eta_{B}\left(u_{i}\right)\right|\right\} \leq\left|\eta_{A}\left(u_{i}\right)-\eta_{C}\left(u_{i}\right)\right|$,

and

$\max \left\{\left|\gamma_{B}\left(u_{i}\right)-\gamma_{A}\left(u_{i}\right)\right|,\left|\gamma_{C}\left(u_{i}\right)-\gamma_{B}\left(u_{i}\right)\right|\right\} \leq\left|\gamma_{A}\left(u_{i}\right)-\gamma_{C}\left(u_{i}\right)\right|$

for all $u_{i} \in U$.

This means that $\max \left\{D I S_{E}^{i}(A, B), D I S_{E}^{i}(B, C)\right\} \leq D I S_{E}^{i}(A, C)$ for all $u_{i} \in U$.

This leads to $\max \left\{D I S_{E}(A, B), D I S_{E}(B, C)\right\} \leq D I S_{E}(A, C)$.

\section{Comparisons to existing dissimilarity measures of picture fuzzy sets}

In this section, we compare the new dissimilarity measure with several existing dissimilarity measures of picture fuzzy sets.

Given $U=\left\{u_{1}, u_{2}, \ldots, u_{n}\right\}$ is an universe set. Given two picture fuzzy sets $A, B \in P F S(U)$. We have some dissimilarity measures of the picture fuzzy sets (Dinh et al., 2017):

$D M_{C}(A, B)=\frac{1}{3 n} \sum_{i=1}^{n}\left[\left|S_{A}\left(u_{i}\right)-S_{B}\left(u_{i}\right)\right|+\left|\eta_{A}\left(u_{i}\right)-\eta_{B}\left(u_{i}\right)\right|\right]$

where $S_{A}\left(u_{i}\right)=\left|\mu_{A}\left(u_{i}\right)-\gamma_{A}\left(u_{i}\right)\right|$ and $S_{B}\left(u_{i}\right)=\left|\mu_{B}\left(u_{i}\right)-\gamma_{B}\left(u_{i}\right)\right|$.

$D M_{H}(A, B)=\frac{1}{3 n} \sum_{i=1}^{n}\left[\left|\mu_{A}\left(u_{i}\right)-\mu_{B}\left(u_{i}\right)\right|+\left|\eta_{A}\left(u_{i}\right)-\eta_{B}\left(u_{i}\right)\right|+\left|\gamma_{A}\left(u_{i}\right)-\gamma_{B}\left(u_{i}\right)\right|\right]$

$D M_{L}(A, B)=\frac{1}{5 n} \sum_{i=1}^{n}\left[\left|S_{A}\left(u_{i}\right)-S_{B}\left(u_{i}\right)\right|+\left|\mu_{A}\left(u_{i}\right)-\mu_{B}\left(u_{i}\right)\right|+\left|\eta_{A}\left(u_{i}\right)-\eta_{B}\left(u_{i}\right)\right|+\mid \gamma_{A}\left(u_{i}\right)-\right.$ $\left.\gamma_{B}\left(u_{i}\right) \mid\right](4)$

$D M_{O}(A, B)=\frac{1}{\sqrt{3 n}} \sum_{i=1}^{n}\left[\left|\mu_{A}\left(u_{i}\right)-\mu_{B}\left(u_{i}\right)\right|^{2}+\left|\eta_{A}\left(u_{i}\right)-\eta_{B}\left(u_{i}\right)\right|^{2}+\left|\gamma_{A}\left(u_{i}\right)-\gamma_{B}\left(u_{i}\right)\right|^{2}\right]^{\frac{1}{2}}$

These measures have a restriction, which is shown in the following example: follows:

Example 1. Assume that there are two patterns denoted by picture fuzzy sets on $U=\left\{u_{1}, u_{2}\right\}$ as

$A_{1}=\left\{\left(u_{1}, 0,0,0\right),\left(u_{2}, 0.1,0,2,0.1\right)\right\}$ and

$A_{2}=\left\{\left(u_{1}, 0,0,0.1\right),\left(u_{2}, 0.2,0.2,0.1\right)\right\}$.

Now, there is a sample $B=\left\{\left(u_{1}, 0,0.1,0.1\right),\left(u_{2}, 0.1,0.1,0.1\right)\right\}$.

Question: Which class of patterns does $B$ belong to?

Using four dissimilarity measures in the Eq.(2), Eq.(3), Eq.(4), and Eq.(5) we have

$+D M_{C}\left(A_{1}, B\right)=D M_{C}\left(A_{2}, B\right)=0.05$,

$+D M_{L}\left(A_{1}, B\right)=D M_{L}\left(A_{2}, B\right)=0.04$,

$+D M_{H}\left(A_{1}, B\right)=D M_{H}\left(A_{2}, B\right)=0.05$, and

$+D M_{O}\left(A_{1}, B\right)=D M_{O}\left(A_{2}, B\right)=0.0986$.

We can easily see that $B$ does not belong to the class of pattern $A_{1}$ or the class of pattern $A_{2}$.

Meanwhile, if using the new dissimilarity measure in Eq.(1) then we have

$D M_{C}\left(A_{1}, B\right)=0.05, D M_{C}\left(A_{2}, B\right)=0.0491$. 
We can easily see that sample $B$ belongs to the class of pattern $A_{2}$.

This example shows that our proposed dissimilarity measure has overcome the restriction of four dissimilarity measures of picture fuzzy sets which was introduced by Dinh et al. (2017).

\section{The proposed MCDM method}

In this section, we propose a new method for multi-criteria decision making problems using the new dissimilarity measure of picture fuzzy sets. The multi-criteria decision making problem is determined to be the best alternative from the concepts of the compromise solution. The best compromise solution is the alternative which obtains the smallest dissimilarity measure from each alternative to the perfect choice. The procedures of the proposed method can be expressed as follows.

Input: Let $A=\left\{A_{1}, A_{2}, \ldots, A_{m}\right\}$ be the set of alternatives and $C=\left\{C_{1}, C_{2}, \ldots, C_{n}\right\}$ be the set of criteria with the weight of each criteria $C_{j}$ is $w_{j}$ where $j=1,2, \ldots, n$ and $\sum_{j=1}^{n} w_{j}=1$. For each alternative, $A_{i}(i=1,2, \ldots, m)$ is a picture fuzzy set on $\mathrm{C}$, which means that:

$$
A_{i}=\left\{\left(C_{j}, d_{i j}^{1}, d_{i j}^{2}, d_{i j}^{3}\right) \mid C_{j} \in C\right\} .
$$

The picture fuzzy decision making matrix $D=\left(d_{i j}\right)$ in which $d_{i j}=\left(d_{i j}^{1}, d_{i j}^{2}, d_{i j}^{3}\right)$ is a picture fuzzy number for all $j=1,2, \ldots, n$ and $i=1,2, \ldots, m$ is as follows:

$$
\begin{gathered}
D \\
A_{1} \\
A_{2} \\
\vdots \\
A_{m}
\end{gathered} \quad\left(\begin{array}{cccc}
d_{11} & C_{2} & \ldots & d_{n} \\
d_{21} & d_{22} & \ldots & d_{1 n} \\
\vdots & \vdots & \ldots & d_{2 n} \\
d_{m 1} & d_{m 2} & \cdots & d_{m n}
\end{array}\right)
$$

Output: Ranking of alternatives

The proposed method is presented with the following steps.

\section{Step 1. Normalizing the decision matrix}

In this step, we construct the picture fuzzy decision making matrix. For instance, the $\mathrm{j}_{-}$th column of the decision making matrix is the natural number (but does not form the picture fuzzy number)

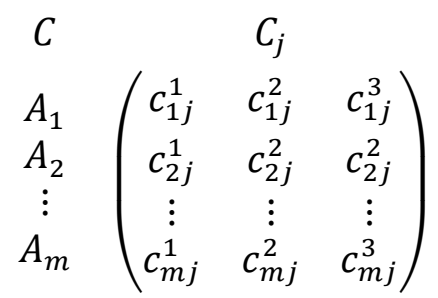

where $c_{i j}^{k}>0$ for all $i=1,2, \ldots, m$ and $j=1,2, \ldots, n ; k=1,2,3$. We will calculate

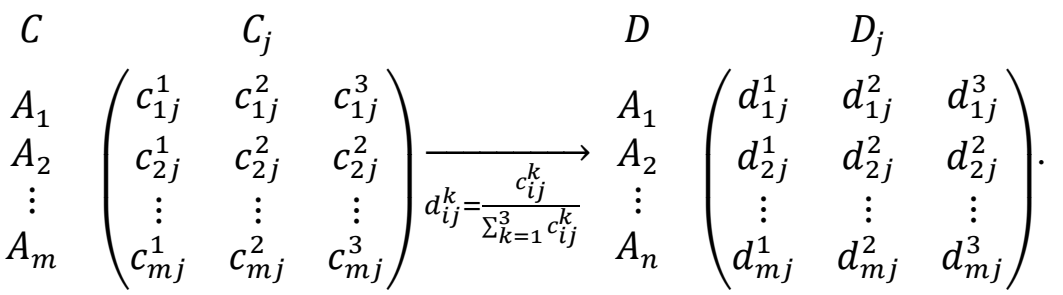

Then $D=\left(d_{i j}\right)$ in which $d_{i j}=\left(d_{i j}^{1}, d_{i j}^{2}, d_{i j}^{3}\right)$ is a picture fuzzy decision making matrix.

This step is ignored if matrix $D$ is the given picture fuzzy decision making matrix. 


\section{Step 2. Determining the weight of each criteria}

We determine the weight $w_{j}(j=1,2, \ldots, n)$ of the criteria $C_{j}(j=1,2, \ldots, n)$ such that $\sum_{j=1}^{n} w_{j}=1$.

For instance $w_{j}=\frac{d_{j}}{\sum_{j}^{n} d_{j}}$

where $d_{j}=d_{1 j}+d_{2 j}+d_{3 j}$ and $d_{1 j}=\max _{i=1,2, \ldots, m} d_{i j}^{1}, d_{2 j}=\min _{i=1,2, \ldots, m} d_{i j}^{2}, d_{3 j}=\min _{i=1,2, \ldots, m} d_{i j}^{3}$ for all $j=1,2, \ldots, n$.

Note that $\left(d_{1 j}, d_{2 j}, d_{3 j}\right)(j=1,2, \ldots, n)$ are picture fuzzy numbers.

\section{Step 3. Determining the perfect choice}

In this section, we determine the perfect choice. Here, we pay attention to the benefit criteria and cost criteria. Usually, with the perfect choices, we can take the picture fuzzy number $(1,0,0)$ for the benefit criteria and $(0,0,1)$ for the cost criteria. Note that $(1,0,0)$ is the largest value of a picture fuzzy linguistic and $(0,0,1)$ is the smallest value of a picture fuzzy linguistic. Thus, the perfect choice $A_{b}$ gets the picture fuzzy number $A_{b}(j)$ at the criteria $C_{j}$, in which $A_{b}(j)=(1,0,0)$ if $C_{j}$ is the benefit criteria and $A_{b}(j)=(0,0,1)$ if $C_{j}$ is the cost criteria, for all $j=1,2, \ldots, n$.

\section{Step 4. Calculating the dissimilarity measure of each alternative to the perfect choice}

From Eq.(1) we have the dissimilarity measure of each alternative and the perfect choice which are calculated by

$$
D I S_{E}\left(A_{i}, A_{b}\right)=\sum_{j=1}^{n} w_{j} D I S_{E}^{j}\left(\mathrm{~A}_{\mathrm{i}}, \mathrm{A}_{\mathrm{b}}\right), i=1,2, \ldots, m
$$

\section{Step 5. Ranking the alternatives}

Now, we can rank the alternatives based on the dissimilarity measure of the each alternative and the perfect choice as follows

$$
\begin{aligned}
& A_{i_{1}} \prec A_{i_{2}} \text { iff } \operatorname{DIS}\left(A_{i_{1}}, A_{b}\right)>\operatorname{DIS}\left(A_{i_{2}}, A_{b}\right) \\
& A_{i_{1}} \simeq A_{i_{2}} \text { iff } \operatorname{DIS}\left(A_{i_{1}}, A_{b}\right)=\operatorname{DIS}\left(A_{i_{2}}, A_{b}\right) .
\end{aligned}
$$

\section{The proposed method for evaluating water reuse applications}

In this section, we use our proposed method presented in section 3 to evaluate water reuse applications. The data were taken from Pan et al. (2018). The problem is as follows. There are seven alternative water reuse systems, namely $A_{1}$ : toilet flushing (TF); $A_{2}$ : vegetable watering in gardens $(\mathrm{VW}) ; A_{3}$ : flower watering in gardens $(\mathrm{FW}) ; A_{4}$ : agricultural irrigation (AI); $A_{5}$ : public parks watering (PPW); $A_{6}$ : golf course watering $(\mathrm{GCW})$; and $A_{7}$ : drinking water (DW). We need to determine the best option based on five specific criteria, namely $C_{1}$ : public acceptability (PA); $C_{2}$ : freshwater saving (FS); $C_{3}$ : life cycle cost (LCC); $C_{4}$ : human health risk (HHR); and $C_{5}$ : the local governments' polices (GP).

The criteria data for public acceptability, freshwater saving, life cycle cost and human health risk were collected as positive real numbers. Data for the governments' policies was given in the form of linguistic variables. All the collected data are shown in Tables 1 and 2 . The value picture fuzzy numbers of the linguistic variables are shown in Table 3.

We consider that $C_{1}, C_{2}, C_{5}$ are the benefit criteria and $C_{3}, C_{4}$ are the cost criteria.

Now, we present the process of our method for evaluating the water reuse applications.

\section{Step 1. Normalizing the decision matrix}

From Eq.(6), we obtain the normalization decision matrix (Table 4). 
A novel multi-criteria decision making method for evaluating water reuse applications under uncertainty

Table 1. Public acceptability and freshwater saving data

\begin{tabular}{|c|c|c|c|c|c|c|}
\hline \multirow[t]{2}{*}{ Alternatives } & \multicolumn{3}{|c|}{$C_{1}:$ public acceptability } & \multicolumn{3}{|c|}{$C_{2}$ : freshwater saving (ML/year) } \\
\hline & Agreement & Neutrality & Disagreement & Low & Mid & High \\
\hline $\operatorname{TF}\left(A_{1}\right)$ & 80 & 9 & 11 & 428.8 & 536 & 643.2 \\
\hline $\operatorname{VW}\left(A_{2}\right)$ & 63.5 & 13 & 23.5 & 2624.8 & 3281 & 3937.2 \\
\hline $\mathrm{FW}\left(A_{3}\right)$ & 84.5 & 10 & 5.5 & 3192.5 & 3990.6 & 4788.8 \\
\hline $\mathrm{Al}\left(A_{4}\right)$ & 74.5 & 10 & 15.5 & 3192.5 & 3990.6 & 4788.8 \\
\hline $\operatorname{PPW}\left(A_{5}\right)$ & 85.5 & 8 & 6.5 & 886.3 & 1107.9 & 1329.5 \\
\hline $\operatorname{GCW}\left(A_{6}\right)$ & 88.5 & 7 & 4.5 & 361.8 & 452.3 & 542.7 \\
\hline $\mathrm{DW}\left(A_{7}\right)$ & 24 & 14 & 62 & 3192.5 & 3990.6 & 4788.8 \\
\hline
\end{tabular}

Table 2. Life cycle cost, human health risk, and government policies data

\begin{tabular}{|c|c|c|c|c|c|c|c|}
\hline \multirow[t]{2}{*}{ Alternatives } & \multicolumn{3}{|c|}{$C_{3}:$ life cycle cost (USD/year) } & \multicolumn{3}{|c|}{$\begin{array}{c}C_{4}: \text { human health risk } \\
\text { (DALY/capita/year) }\end{array}$} & \multirow{2}{*}{$\begin{array}{c}C_{5}: \text { governments' } \\
\text { policies }\end{array}$} \\
\hline & Low & Mid & High & Low & Mid & High & \\
\hline $\operatorname{TF}\left(A_{1}\right)$ & 1555358 & 1944198 & 2333038 & 7.10E-12 & $7.51 \mathrm{E}-12$ & 8.30E-12 & M (Moderate) \\
\hline $\operatorname{VW}\left(A_{2}\right)$ & 1637219 & 2046524 & 2455829 & $1.83 \mathrm{E}-11$ & $1.89 \mathrm{E}-11$ & $2.03 \mathrm{E}-11$ & L (Low) \\
\hline $\mathrm{FW}\left(A_{3}\right)$ & 834019 & 1042524 & 1251028 & $1.78 \mathrm{E}-11$ & $1.84 \mathrm{E}-11$ & $1.99 \mathrm{E}-11$ & $\mathrm{H}$ (High) \\
\hline $\mathrm{Al}\left(A_{4}\right)$ & 146660 & 183326 & 219991 & $9.07 \mathrm{E}-12$ & $1.00 \mathrm{E}-11$ & $1.26 \mathrm{E}-11$ & M (Moderate) \\
\hline $\operatorname{PPW}\left(A_{5}\right)$ & 635529 & 794411 & 953293 & $9.34 \mathrm{E}-12$ & $9.77 \mathrm{E}-12$ & $1.07 \mathrm{E}-11$ & $\mathrm{H}$ (High) \\
\hline $\operatorname{GCW}\left(A_{6}\right)$ & 78219 & 97774 & 117328 & $8.43 \mathrm{E}-12$ & $8.87 \mathrm{E}-12$ & $9.83 \mathrm{E}-12$ & M (Moderate) \\
\hline $\operatorname{DW}\left(A_{7}\right)$ & 1197674 & 1497092 & 1796511 & $2.76 \mathrm{E}-08$ & $4.01 \mathrm{E}-08$ & $1.00 \mathrm{E}-07$ & VL (Very low) \\
\hline
\end{tabular}

Table 3. The picture fuzzy number of linguistic variables

\begin{tabular}{cc}
\hline Linguistic variables & Picture fuzzy number \\
\hline M & $(0.5,0.4,0.1)$ \\
L & $(0.2,0.5,0.3)$ \\
H & $(0.8,0.1,0.05)$ \\
M & $(0.5,0.4,0.1)$ \\
H & $(0.8,0.1,0.05)$ \\
M & $(0.5,0.4,0.1)$ \\
VL & $(0.1,0,0.9)$ \\
\hline
\end{tabular}

Table 4. Decision matrix

\begin{tabular}{cccc}
\hline & $C_{1}$ & $C_{2}$ & $C_{3}$ \\
\hline$A_{1}$ & $(0.8,0.09,0.11)$ & $(0.266667,0.333333,0.4)$ & $(0.266667,0.333333,0.4)$ \\
$A_{2}$ & $(0.635,0.13,0.235)$ & $(0.266667,0.333333,0.4)$ & $(0.266667,0.333333,0.4)$ \\
$A_{3}$ & $(0.845,0.1,0.055)$ & $(0.266666,0.333331,0.400003)$ & $(0.266667,0.333333,0.4)$ \\
$A_{4}$ & $(0.745,0.1,0.155)$ & $(0.266666,0.333331,0.400003)$ & $(0.266666,0.333334,0.4)$ \\
$A_{5}$ & $(0.855,0.08,0.065)$ & $(0.266661,0.333333,0.400006)$ & $(0.266667,0.333333,0.4)$ \\
$A_{6}$ & $(0.885,0.07,0.045)$ & $(0.266657,0.333358,0.399985)$ & $(0.266667,0.333333,0.399999)$ \\
$A_{7}$ & $(0.24,0.14,0.14)$ & $(0.266666,0.333331,0.400003)$ & $(0.266667,0.333333,0.4)$ \\
\hline
\end{tabular}


Table 4. Decision matrix (cont.)

\begin{tabular}{ccc}
\hline & $C_{4}$ & $C_{5}$ \\
\hline$A_{1}$ & $(0.309908,0.327804,0.362287)$ & $(0.5,0.4,0.1)$ \\
$A_{2}$ & $(0.318261,0.328696,0.353043)$ & $(0.2,0.5,0.3)$ \\
$A_{3}$ & $(0.317291,0.327986,0.354724)$ & $(0.8,0.1,0.05)$ \\
$A_{4}$ & $(0.286391,0.315756,0.397853)$ & $(0.5,0.4,0.1)$ \\
$A_{5}$ & $(0.313318,0.327742,0.35894)$ & $(0.8,0.1,0.05)$ \\
$A_{6}$ & $(0.310726,0.326944,0.36233)$ & $(0.5,0.4,0.1)$ \\
$A_{7}$ & $(0.16458,0.239117,0.596303)$ & $(0.1,0,0.9)$ \\
\hline
\end{tabular}

\section{Step 2. Determining the weight of the criteria}

From Eq.(7), we get the weights $w_{j}$ of criteria $C_{j}$ are $w_{1}=w_{2}=w_{3}=0.21, w_{4}=0.19, w_{5}=$ 0.18 .

\section{Step 3. Determining the perfect choice}

The perfect choice is

$A_{b}=\left(A_{b}(1), A_{b}(2), A_{b}(3), A_{b}(4), A_{b}(5)\right)$

where $A_{b}(1)=A_{b}(2)=A_{b}(5)=(1,0,0)$ and $A_{b}(3)=A_{b}(4)=(0,0,1)$.

\section{Step 4. Calculating the dissimilarity measure of each alternative to the perfect choice}

The dissimilarity measure of each alternative and the perfect choice is calculated by Eq.(8) (Table 5).

$$
\begin{aligned}
& D I S_{E}\left(A_{1}, A_{b}\right)=0.325, D I S_{E}\left(A_{2}, A_{b}\right)=0.3719, D I S_{E}\left(A_{3}, A_{b}\right)=0.2848, \\
& D S_{E}\left(A_{4}, A_{b}\right)=0.3341, D I S_{E}\left(A_{5}, A_{b}\right)=0.2839, D I S_{E}\left(A_{6}, A_{b}\right)=0.3139, \\
& D I S_{E}\left(A_{7}, A_{b}\right)=0.4383 .
\end{aligned}
$$

\section{Step 5. Ranking the alternatives}

We use Eq.(9) to rank the alternatives based on the dissimilarity measure of each alternative and the perfect choice

$A_{7} \prec A_{2} \prec A_{4} \prec A_{1} \prec A_{6} \prec A_{3} \prec A_{5}$

This result shows that alternative $A_{5}$ (Public parks watering (PPW)) is the best choice (Table 5).

Table 5. Ranking of alternatives

\begin{tabular}{lcc}
\hline \multicolumn{1}{c}{ Alternatives } & $D I S_{E}\left(A_{i}, A_{b}\right)$ & Rank \\
\hline TF & 0.3250 & 4 \\
VW & 0.3719 & 6 \\
FW & 0.2848 & 2 \\
Al & 0.3341 & 5 \\
PPW & 0.2839 & 1 \\
GCW & 0.3139 & 3 \\
DW & 0.4383 & 7 \\
\hline
\end{tabular}

If we consider the same weight for all criteria $\left(w_{j}=0.2, j=1,2, \ldots, 5\right)$, we have the results as shown in Table 6. 
Table 6. Ranking of alternatives with the same weight for all criteria

\begin{tabular}{lcc}
\hline \multicolumn{1}{c}{ Alternatives } & $D I S_{E}\left(A_{i}, A_{b}\right)$ & Rank \\
\hline TF & 0.3256 & 4 \\
VW & 0.3745 & 6 \\
FW & 0.2819 & 2 \\
Al & 0.3345 & 5 \\
PPW & 0.2810 & 1 \\
GCW & 0.3150 & 3 \\
DW & 0.4405 & 7 \\
\hline
\end{tabular}

Table 7. Ranking of the alternatives with different weight vectors

\begin{tabular}{lcccccc}
\hline \multirow{2}{*}{ Alternatives } & \multicolumn{2}{c}{$w 1=(0.1,0.2,0.2,0.4,0.1)$} & \multicolumn{2}{c}{$w 2=(0.25,0.25,0.25,0.25,0)$} & \multicolumn{2}{c}{$w 3=(0,0.25,0.25,0.25,0.25)$} \\
\cline { 2 - 7 } & $D I S_{E}\left(A_{i}, A_{b}\right)$ & Rank & $D I S_{E}\left(A_{i}, A_{b}\right)$ & Rank & $D I S_{E}\left(A_{i}, A_{b}\right)$ & Rank \\
\hline TF & 0.3623 & 4 & 0.3325 & 4 & 0.3752 & 4 \\
VW & 0.3855 & 6 & 0.3556 & 6 & 0.4123 & 6 \\
FW & 0.3394 & 1 & 0.3247 & 3 & 0.3274 & 1 \\
Al & 0.3703 & 5 & 0.3437 & 5 & 0.3781 & 5 \\
PPW & 0.3395 & 2 & 0.3237 & 2 & 0.3279 & 2 \\
GCW & 0.3569 & 3 & 0.3139 & 1 & 0.3751 & 3 \\
DW & 0.4461 & 7 & 0.4262 & 7 & 0.4430 & 7 \\
\hline
\end{tabular}

Table 8. Comparing the ranking results of our method and the ranking results of Pan et al. (2018) with the same weight for all the criteria

\begin{tabular}{lccccc}
\hline \multirow{2}{*}{ Alternatives } & \multicolumn{5}{c}{ Rank } \\
\cline { 2 - 6 } & Our method & Pro-economy & Pro-social & Pro-environment & WRAE with a generalized parameter \\
\hline TF & 4 & 5 & 5 & 5 & 5 \\
VW & 6 & 6 & 6 & 6 & 6 \\
FW & 2 & 2 & 1 & 1 & 1 \\
Al & 5 & 4 & 4 & 3 & 4 \\
PPW & 1 & 1 & 2 & 2 & 3 \\
GCW & 3 & 3 & 3 & 4 & 7 \\
DW & 7 & 7 & 7 & 7 & \\
\hline
\end{tabular}

Now, we give examples of results using our method with the different weight vectors. For instance, with $w 1$ we considered human health risk criteria more important than others; with $w 2$ we ignored the government policy criteria; and with $w 3$ we dismissed the public acceptability criteria. These results are shown in Table 7. Finally, we also recalled the results cited in Pan et al. (2018) in Table 8.

\section{Conclusions}

In this paper, we introduced a new dissimilarity measure (in Eq.(1)). After that, we introduced a MCDM using the dissimilarity measure of picture fuzzy sets. Finally, we applied the proposed method to evaluate water reuse applications. When the weights changed, i.e. the priority for the criteria changed, the results also changed. In Pan et al. (2018), the authors used the hesitation of the fuzzy soft sets and combined this with the score function of them to evaluate the water reuse applications under uncertainty. This is the complexity of the methods of Pan et al. (2018). By characterizing the data of the water reuse applications in Pan et al. (2018), we find that the use of picture fuzzy sets can be applied to this problem. Our method represents a 
new approach to this problem and the calculation is simpler than Pan's. In the future, we plan to further apply this method to other problems as well as to study new cities to apply this method to help resolve practical problems.

\section{Acknowledgements}

We would like to thank the financial support of Vietnam National University of Agriculture for the project code T2018-10-69.

\section{References}

Atanassov K. T. (1986). Intuitionistic fuzzy sets. Fuzzy sets and Systems. Vol 20 (1). pp. 87-96.

Bhutia P. W. and Phipon R. (2012). Application of AHP and TOPSIS method for supplier selection problem. IOSR Journal of Engineering. Vol 2 (10). pp. 43-50.

Boran F. E., Genç S., Kurt M. and Akay D. (2009). A multi-criteria intuitionistic fuzzy group decision making for supplier selection with TOPSIS method. Expert Systems with Applications. Vol 36 (8). pp. 11363-11368.

Cuong B. C. and Kreinovich V. (2013). Picture Fuzzy Sets-a new concept for computational intelligence problems. In the $3^{\text {rd }}$ World Congress on Information and Communication Technologies (WICT'2013), December 15-18 2013, Hanoi, Vietnam. pp. 1-6.

Dinh N. V., Thao N. X. and Chau N. M. (2015). On the picture fuzzy database: theories and application. Journal of Science and Development. Vol 13 (6). pp. 1028-1035.

Dinh N. V., Thao N. X. and Chau N. M. (2017). Some dissimilarity measures of picture fuzzy set. In the $10^{\text {th }}$ Fundamental and Applied IT Research (FAIR'2017), August 17-18, 2017, Danang, Vietnam. pp. 104-109.

Hoa N. D. and Thong P. H. (2017). Some Improvements of Fuzzy Clustering Algorithms Using Picture Fuzzy Sets and Applications for Geographic Data Clustering. VNU Journal of Science: Computer Science and Communication Engineering. Vol 32 (3). pp. 32-38.

Jadidi O., Firouzi F. and Bagliery E. (2010). TOPSIS method for supplier selection problem. World Academy of Science, Engineering and Technology. Vol 47. pp. 956-958.

Kavita, Yadav S. P. and Kumar S. (2009). A multi-criteria interval-valued intuitionistic fuzzy group decision making for supplier selection with TOPSIS method. Lecture Notes in Computer Science. Vol 5908. pp. 303-312.
Maldonado-Macías A., Alvarado A., García J. L. and Balderrama C. O. (2014). Intuitionistic fuzzy TOPSIS for ergonomic compatibility evaluation of advanced manufacturing technology. The International Journal of Advanced Manufacturing Technology. Vol 70 (912). pp. 2283-2292.

Miller G. W. (2006). Integrated concepts in water reuse: managing global water needs. Desalination. Vol 187. pp. 65-75.

Omorogbe D. E. A. (2016). A review of intuitionistic fuzzy topsis for supplier selection. AFRREV STECH: An International Journal of Science and Technology. Vol 5 (2). pp. 91-102.

Pan Q., Chhipi-Shrestha G., Zhou D., Zhang K., Hewage K. and Sadiq R. (2018). Evaluating water reuse applications under uncertainty: generalized intuitionistic fuzzy-based approach. Stochastic Environmental Research and Risk Assessment. Vol 32 (4). pp. 1099-1111.

Pérez-Domínguez L., Alvarado-Iniesta A., RodríguezBorbón I. and Vergara-Villegas O. (2015). Intuitionistic fuzzy MOORA for supplier selection. Dyna. Vol 82 (191). pp. 34-41.

Solanki R., Gulati G., Tiwari A. and Lohani Q. M. D. (2016). A correlation based Intuitionistic fuzzy TOPSIS method on supplier selection problem. In 2016 IEEE International Conference on Fuzzy Systems (FUZZ-IEEE), July 24-29, 2016, Vancouver, Canada. pp. 2106-2112.

Son L. H. (2015). DPFCM: A novel distributed picture fuzzy clustering method on picture fuzzy sets. Expert Systems with Applications. Vol 42. pp. 51-66.

Son L. H. (2017). Measuring analogousness in picture fuzzy sets: from picture distance measures to picture association measures. Fuzzy Optimization and Decision Making. Vol 16 (3). pp. 359-378.

Yayla A. Y., Yildiz A. and Özbek A. (2012). Fuzzy TOPSIS method in supplier selection and application in the garment industry. Fibres and Textiles in Eastern Europe. Vol 4 (93). pp. 20-23.

Yildiz A. and Yayla A. Y. (2015). Multi-criteria decisionmaking methods for supplier selection: A literature review. South African Journal of Industrial Engineering. Vol 26 (2). pp. 158-177.

Zadeh L. A. (1965). Fuzzy sets. Information and Control. Vol 8 (3). pp. 338-353.

Zarghami M. and Szidarovszky F. (2009). Stochasticfuzzy multi criteria decision making for robust water resources management. Stochastic Environmental Research and Risk Assessment. Vol 23. pp. 329-339.

Zeng S. and Xiao Y. (2016). TOPSIS method for intuitionistic fuzzy multiple-criteria decision making and its application to investment selection. Kybernetes. Vol 45 (2). pp. 282-296. 